\title{
Stability of Large DC Power Systems Using Switching Converters, With Application to the International Space Station
}

E.W. Gholdston

Rocketdyne Division/Rockwell International

Canoga Park, California

K. Karimi

The Boeing Company

Seattle, Washington

F.C. Lee, J. Rajagopalan, and Y. Panov

Virginia Polytechnic Institute and State University

Blacksburg, Virginia

B. Manners

Lewis Research Center

Cleveland, Ohio

Prepared for the

31st Intersociety Energy Conversion Engineering Conference cosponsored by IEEE, AIChE, ANS, SAE, AIAA, and ASME Washington, DC, August 11-16, 1996

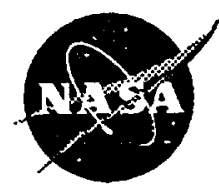

National Aeronautics and Space Administration 


\title{
STABILITY OF LARGE DC POWER SYSTEMS USING SWITCHING CONVERTERS, WITH APPLICATION TO THE INTERNATIONAL SPACE STATION
}

\author{
E. W. Gholdston \\ Rocketdyne Division/Rockwell International \\ 6633 Canoga Avenue \\ Canoga Park, CA 91309 \\ K. Karimi \\ The Boeing Company \\ P.O. Box 3707 \\ Seattle. WA 98124 \\ F. C. Lee, J. Rajagopalan, Y. Panov \\ Virginia Polytechnic Institute and State Univ. \\ 667 Whittenmore Hall \\ Blacksburg, VA 24061-0111 \\ B. Manners \\ NASA Lewis Research Center \\ 21000 Brookpark Road \\ Cleveland, $\mathrm{OH} 44135$
}

\section{ABSTRACT AND INTRODUCTION}

As space direct current (dc) power systems continue to grow in size, switching power converters are playing an ever larger role in power conditioning and control. When designing a large dc system using power converters of this type, special attention must be placed on the electrical stability of the system and of the individual loads on the system. In the design of the electric power system (EPS) of the International Space Station (ISS), the National Aeronautics and Space Administration (NASA) and its contractor team led by Boeing Defense \& Space Group has placed a great deal of emphasis on designing for system and load stability. To achieve this goal, the team has expended considerable effort deriving a clear concept on defining system stability in both a general sense and specifically with respect to the space station. The ISS power system presents numerous challenges with respect to system stability, such as high power, complex sources and undefined loads. To complicate these issues, source and load components have been designed in parallel by three major subcontractors (Boeing, Rocketdyne, and McDonnell Douglas) with interfaces to both sources and loads being designed in different countries (Russia, Japan, Canada, Europe, etc.). These issues, coupled with the program goal of limiting costs, have proven a significant challenge to the program. As a result, the program has derived an impedance specification approach for system stability. This approach is based on the significant relationship between source and load impedances and the effect of this relationship on system stability. This approach is limited in its applicability by the theoretical and practical limits on component designs as presented by each system segment. As a result, the overall approach to system stability implemented by the ISS program consists of specific hardware requirements coupled with extensive system analysis and hardware testing. Following this approach, the ISS program plans to begin construction of the world's largest orbiting power system in 1997.

\section{DISTRIBUTED SYSTEM DESIGN}

Large distributed dc power systems have been used in a variety of applications such as spacecraft power systems (Lee et al. 1988), telecommunications (Yotsumoto 1988), terrestrial computer systems, and medical electronics. These systems use multiple dc-to-dc converters to supply needed power levels at different voltages. Distributed power systems offer many benefits to system designers over central power systems such as reduced weight and size. Distributed systems also allow the designers to control the quality of power at different loads and subsystems, since dc-to-dc converters allow close regulation of output voltage under wide variations of input voltages and loads. Distributed power systems also provide a high degree of reliability because of isolation provided by dc-todc converters; it is very easy to isolate system failures and provide redundancy. These systems are also very flexible and easily expanded.

The ISS power system is a specific case of this kind of distributed system. It is a channelized, load following, dc network of solar arrays, batteries, power converters, switches and cables which route current to all user loads on the station. The completed architecture consists of both the 120-V American and 28-V Russian electrical networks, which are capable of exchanging power through dedicated isolating converters (the American-to-Russian Converter Units [ARCUs] and Russian-to-American Converter Units [RACUs]). The details of the architecture and the function of the specific hardware types have been published earlier, and from its earliest inception provided a basis for the program approach to ensure interactive system stability (Gholdston et al. 1996). The portion of the system from the arrays and batteries to the $6.25-\mathrm{kW}$ dc-to-dc 
converter units (DDCUs) is regulated at $160 \mathrm{~V}$ nominal, and is designated the "primary" system. The DDCUs step the power down to more tightly regulated $120-\mathrm{V}$ individual networks denoted the "secondary" systems. Figure I (a top-level representation of the U.S.-built power system) shows a general branching network from a DDCU, through banks of computer-controlled switchgear (denoted remote power controllers [RPCs]), down to the various load converters. A key factor towards a stable design and operation on the station program is that the secondary systems must be flexible enough to accommodate a wide variety of cable lengths and loads, many of which will be scientific payloads that will not be attached to the power system until several years after the station begins operation.

For a power system of this size and complexity, it is not feasible to design the entire system as a whole. Instead, the system can be defined in terms of several smaller blocks, and each block then designed individually. The individual blocks are then integrated to form a complete system. For ISS networks that include international partner segments, such as the laboratory modules built by the European and Japanese Space Agencies, and the Russian modules, as well as the payload subsystems, all are designed independent of each other. In general, even though the subnetworks are well designed, stability can be an issue after system integration if impedance characteristics are not accounted for in the total design. Otherwise, the potential exists that different subsections may interfere with each other because of LC resonances and/or the input impedance characteristics of the switching dc-to-dc converters. This may result in poor power quality and, in extreme cases, system instability. Consequently, on the space station, it was considered extremely

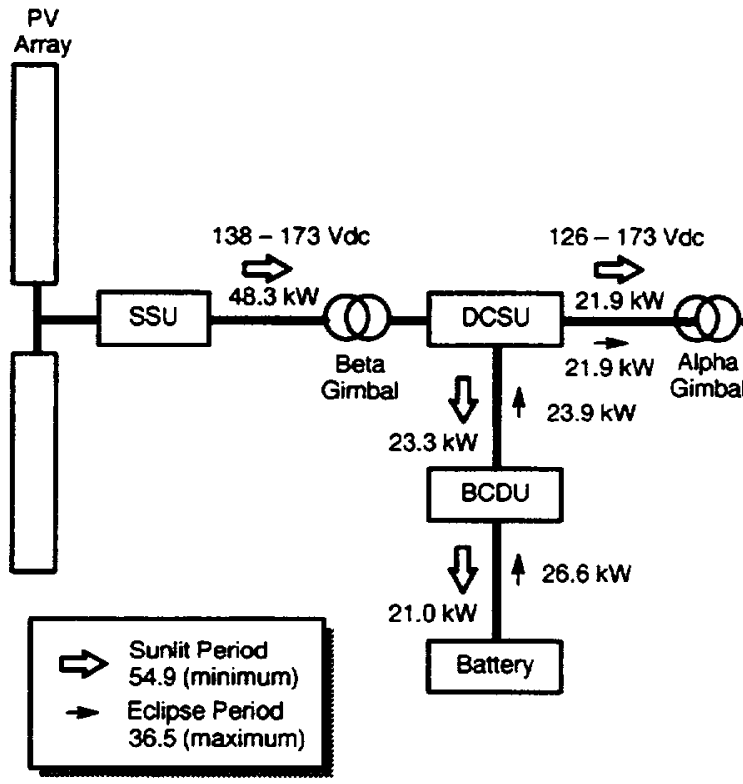

\footnotetext{
Power and voltage values are for 3 years atter $P V$ activation.
}

important to develop proper interface requirements for the subsections, and to further analyze and test these together under various configurations and operating conditions, to ensure system stability after final integration. The approach taken on the Space Station program is based on controlling the impedance of sources and loads.

\section{Interface Impedance Margin Approach}

Practical analytical tools for design of large-scale systems that ensure large-signal stability do not exist at this time. Hence, the approach taken on the Space Station program is based on small-signal considerations of source and load impedances. R. D. Middlebrook (1976) first introduced this approach when he considered the interaction of a dc-to-dc converter and its input electromagnetic interference (EMI) filter. A source impedance $Z_{S}$ was defined as the output impedance of the input EMI filter. The load impedance $Z_{L}$ was defined as the input impedance of the switching regulator. Conditions for stability and performance of the interconnected system were then derived. The same concept can be extended and applied to the integration of various subsections of a large dc power system. Various parts of the system are broken into source and load blocks and source impedance $Z_{S}$ and load impedance $Z_{L}$ are defined for each interface. Figure 2 shows two system blocks connected in series. The source block has an input-to-output transfer function of $T_{S}$, and the load block has an input-to-output transfer function of $T_{L}$.

The input-to-output transfer function of the source/load combination is

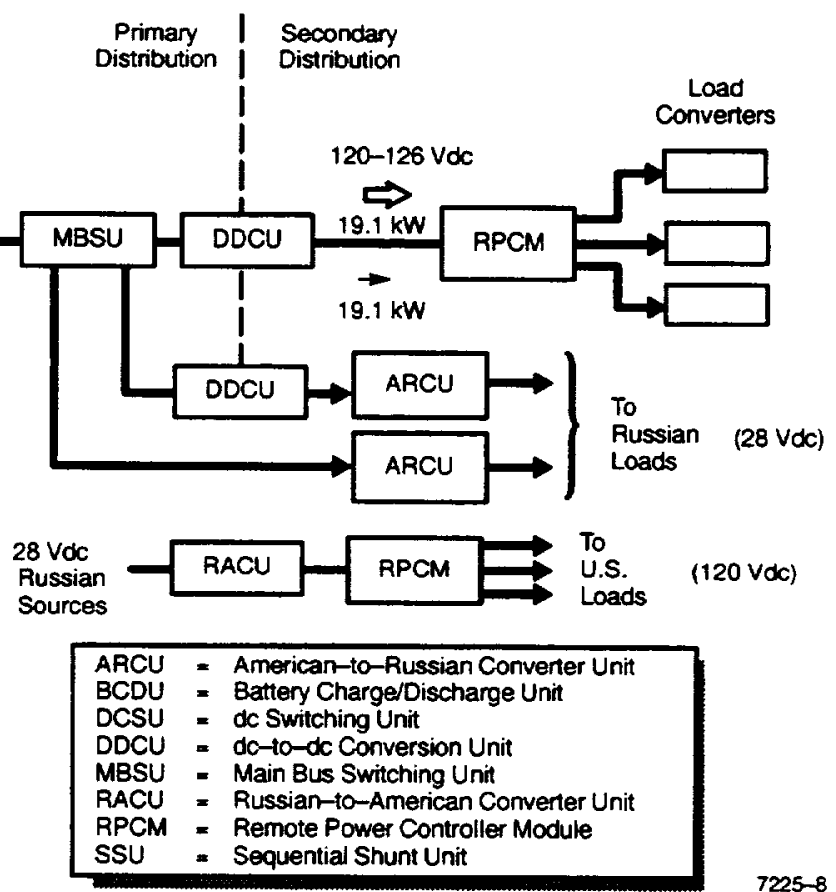

FIGURE 1. SINGLE CHANNEL SYSTEM DIAGRAM OF THE SPACE STATION POWER SYSTEM 


$$
T_{S L}=\frac{T_{s} T_{L}}{1+\left(Z_{s} / Z_{L}\right)}
$$

where, $T_{S L}$ is the input-to-output transfer function of the resulting integrated system, $Z_{S}$ is the output impedance of the source subsystem, and $Z_{L}$ is the input impedance of the load subsystem. The ratio $Z_{S} / Z_{L}=T m$ can be considered as the loop gain of the integrated system, and can be used to determine the stability and loading effects of the integrated system.

If $\left|Z_{S}\right|<\left|Z_{L}\right|$ for all frequencies, then a stable source and load network assures the stability of the connected system. However in most large distributed dc power systems such as the Space Station power system, it is impractical to have $\left|Z_{S}\right|<\left|Z_{\mathbf{L}}\right|$ for all interfaces, since this would require extremely conservative and costly designs. One contributing factor is that paralleling load converters can result in very low input impedance for the aggregate load producing overlap between the source and load impedances across some frequency range. When $\left|Z_{S}\right|>\left|Z_{L}\right|$ considerable loading effects can exist. However, this does not necessarily imply a stability problem. In this case further analysis is needed to determine system stability. In such a case the Nyquist criterion can be applied to the loop gain, Tm. Spe-

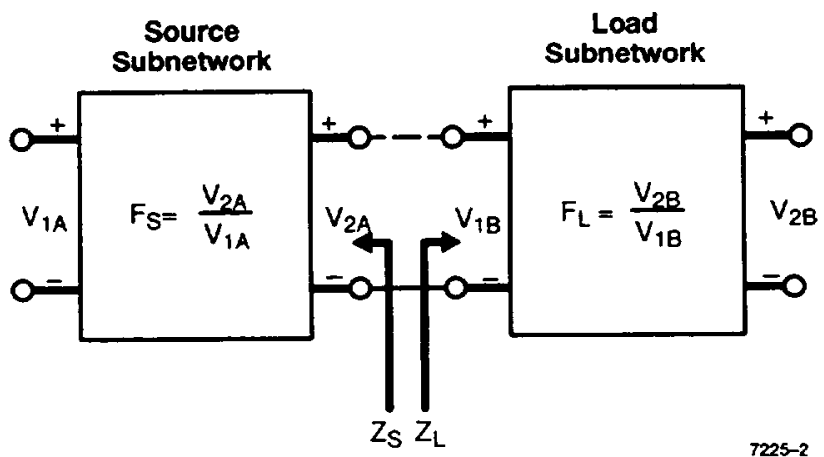

FIGURE 2. TWO SERIES-CONNECTED SUBNETWORKS cifically, for the system to be non-oscillatory, the plot of Tm must not encircle the $(-1,0)$ point in the complex plane. In general, the closer the plot comes to the -1 point the less stable it is, so it is important to determine an acceptable amount of margin consistent with uncertainties and variabilities in operating point and component parameter valves within the system.

The phase and gain margins of the minor loop gain, Tm, can be determined using a polar (Nyquist) plot. (The relationship between the Nyquist and Bode plots is shown in Figure 3).

Figure $4(\mathrm{a}$ and $\mathrm{b})$ shows an example of source and load impedances overlapping. In the frequency region where $\left|Z_{S}\right|>\left|Z_{L}\right|$, the magnitude of the loop gain is larger than $0 \mathrm{~dB}$, Figure $4 \mathrm{c}$ shows the Nyquist plot of $Z_{S} / Z_{L}$, with phase margins and gain margins of $Z_{S} Z_{L}$ identified. Since $Z_{S}$ crosses $Z_{L}$ at two places, two different phase margins are defined as

and

$$
\begin{aligned}
& \mathrm{PM} 1=180^{\circ}-\angle\left(\mathrm{T}_{\mathrm{L}}\right) \\
& \mathrm{PM} 2=\angle\left(\mathrm{T}_{\mathrm{L}}\right)-180^{\circ}
\end{aligned}
$$

The phase margins give a measure of stability as well as the general performance of the system. The bus impedance, which determines the quality of the distribution bus, is defined as the parallel combination of $\mathrm{Z}_{\mathrm{S}}$ and $\mathrm{Z}_{\mathrm{L}}$.

$$
\begin{aligned}
\overrightarrow{\mathrm{Z}}_{\text {bus }}=\overrightarrow{\mathrm{Z}}_{\mathrm{S}} \| \overrightarrow{\mathrm{Z}}_{\mathrm{L}} & =\frac{\overrightarrow{\mathrm{Z}}_{\mathrm{s}}}{1+\mathrm{Z}_{\mathrm{S}} / \mathrm{Z}_{\mathrm{L}}} \\
& =\mathrm{Z}_{\mathrm{S}}\left[\frac{1}{1 \angle 0+\left|\frac{\mathrm{z}_{\mathrm{S}}}{\mathrm{z}_{\mathrm{L}}}\right|<\frac{\mathrm{z}_{\mathrm{S}}}{\mathrm{z}_{\mathrm{L}}}}\right]
\end{aligned}
$$

Thus, the bus impedance is always equal to the source impedance times the factor $(1 / 1+\mathrm{Tm})$. The bus impedance exhibits a peaking when impedance overlap occurs. This peaking happens at the
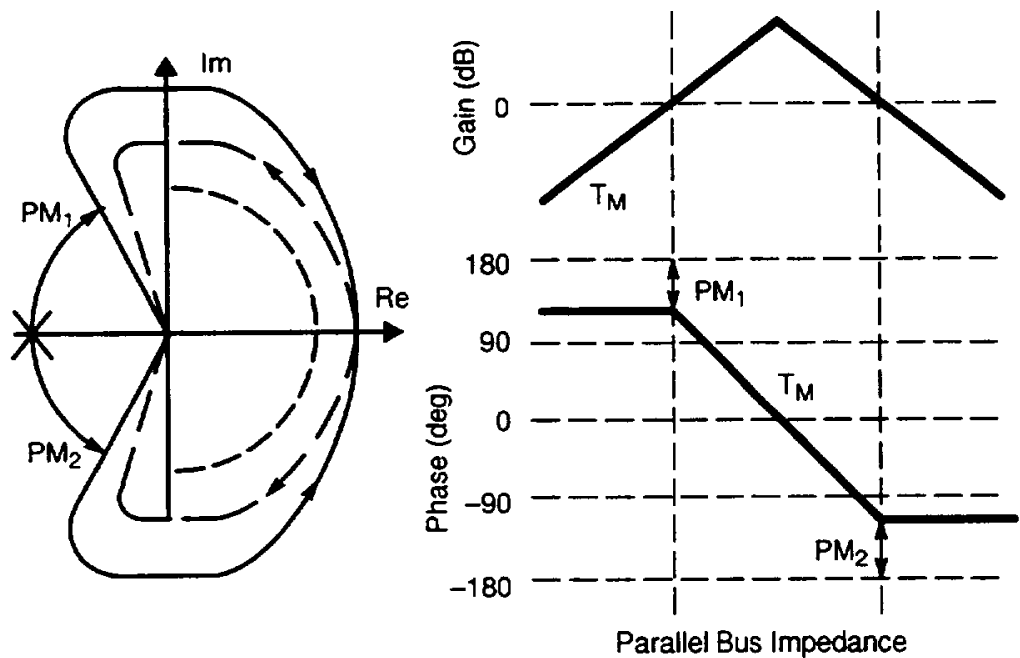

Parallet Bus Impedance

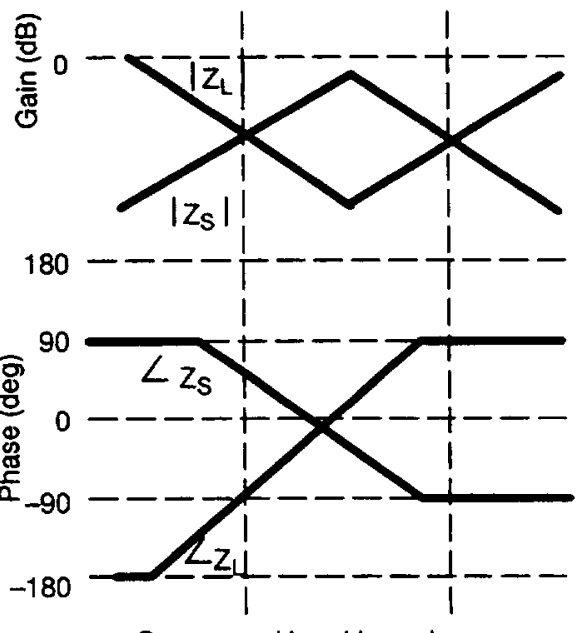

Source and Load Impedance

FIGURE 3. COMPARISON OF NYQUIST AND BODE PLOTS 


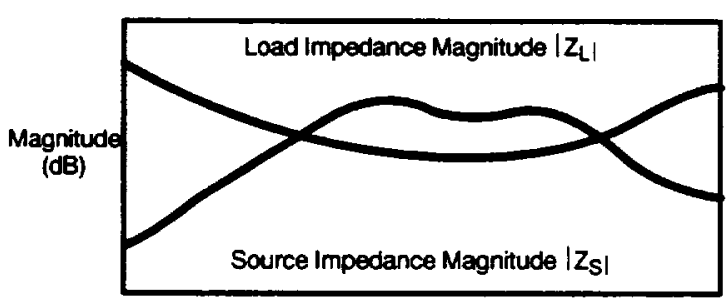

(a) Source and Load Impedance Crossover

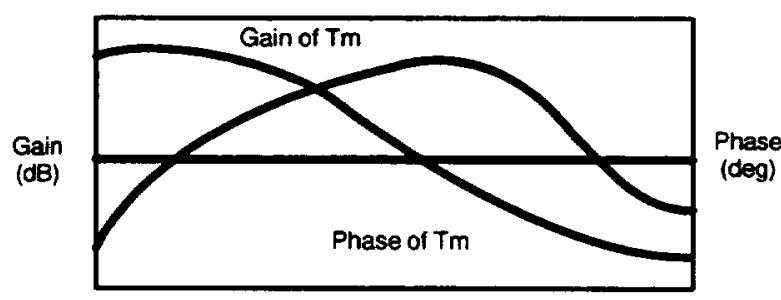

(b) Bode plot of $T m=Z_{S} / Z_{L}$

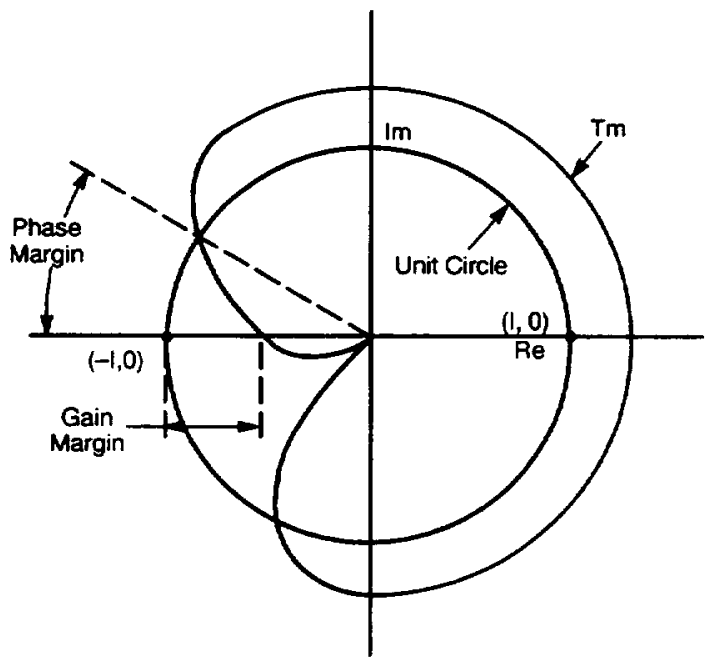

(c) Polar (Nyquist) plot of Tm, showing phase and gain margins

\section{FIGURE 4. IMPEDANCE COMPARISON AT SOURCE/LOAD INTERFACE}

frequency of overlap and is a function of the phase margin. This is illustrated in Figure 5, which shows the result of the vector addition of the two impedances.

When the phase margin is small then the factor is less than one and the value of $Z_{\text {bus }}$ peaks up at the intersection point. Above $60 \mathrm{deg}$ of phase margin the value is less than one, and there is no peaking at all. At 30 deg the amount of peaking is still less than $6 \mathrm{~dB}$, but for phase margins below $30 \mathrm{deg}$ the resonant peak becomes more significant and the associated ringing and bus performance degradation becomes more noticeable. This sets a reasonable lower bound on the desired phase margins in the system, and is the basis for the requirement established on the space station. In
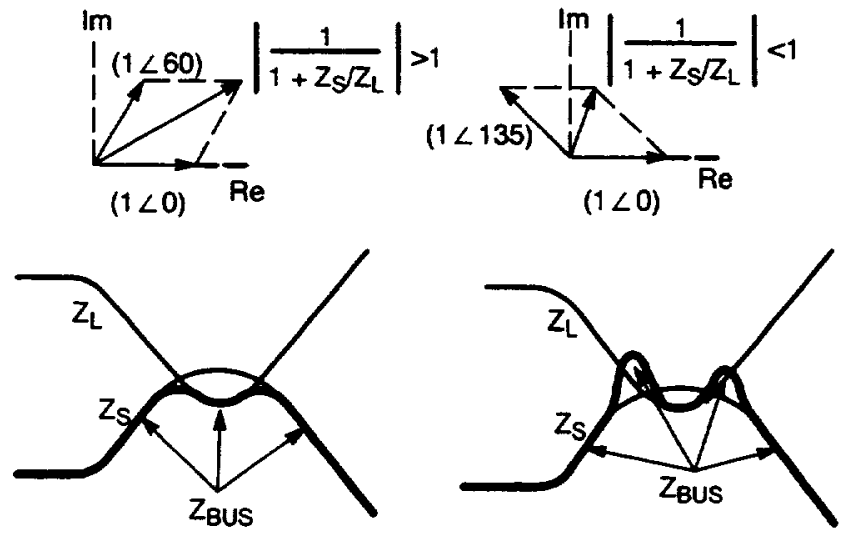

Im = imaginan

$\mathrm{Re}=\mathrm{Real}$

$7225-5$

\section{FIGURE 5. BUS PEAKING FOR LARGE AND SMALL MARGINS}

the primary system, where the converter designs are controlled by a single contractor, the impedances were specified to achieve better than $45 \mathrm{deg}$ of phase margin at key interfaces. In the secondary systems, with wider variability of architectures and loads, a minimum of 30 deg of phase margin is required at the output terminals of the DDCUs.

Correspondingly, in addition to the phase margin, a gain margin also needs to be specified to provide a second buffer near the -1 point on the Nyquist plot. The necessary amount of gain margin (defined when the bus impedance phase is $-180 \mathrm{deg}$, as shown in Fig. 4c) will be a function of the variability of the system, and uncertainties in the hardware parameters over life. For Space Station, based on test and modeling data that were generated by the main contractors of space station hardware, a gain margin of $3 \mathrm{~dB}$ was specified.

\section{System Resonances}

Besides the resonant peaks that can form at source/load impedance crossover points, other resonances can exist in the system. If the system is to be robustly stable (stable under expected perturbations of the system parameters), then these resonances should be minimized to avoid system ringing under excitations at the resonant frequency. Consequently input filters, bus filters, and source converter output filters should be properly damped. To this end the ISS Power Quality specification contains recommendations that input filter quality factors $(\mathrm{Q})$ be below 3.0. Interactions between paralleled load converters can also introduce such resonances and the system must be analyzed carefully to verify that such undesirable conditions do not exist. For the space station, the assembly sequence will span more than 40 launches, so the overall architecture will be constantly changing over the build-up phase on orbit, requiring corresponding stage-by-stage analysis.

\section{Phase and Gain Margins at Key Interfaces}

The next step in establishing a complete set of interface requirements for sources and loads requires some understanding of other 

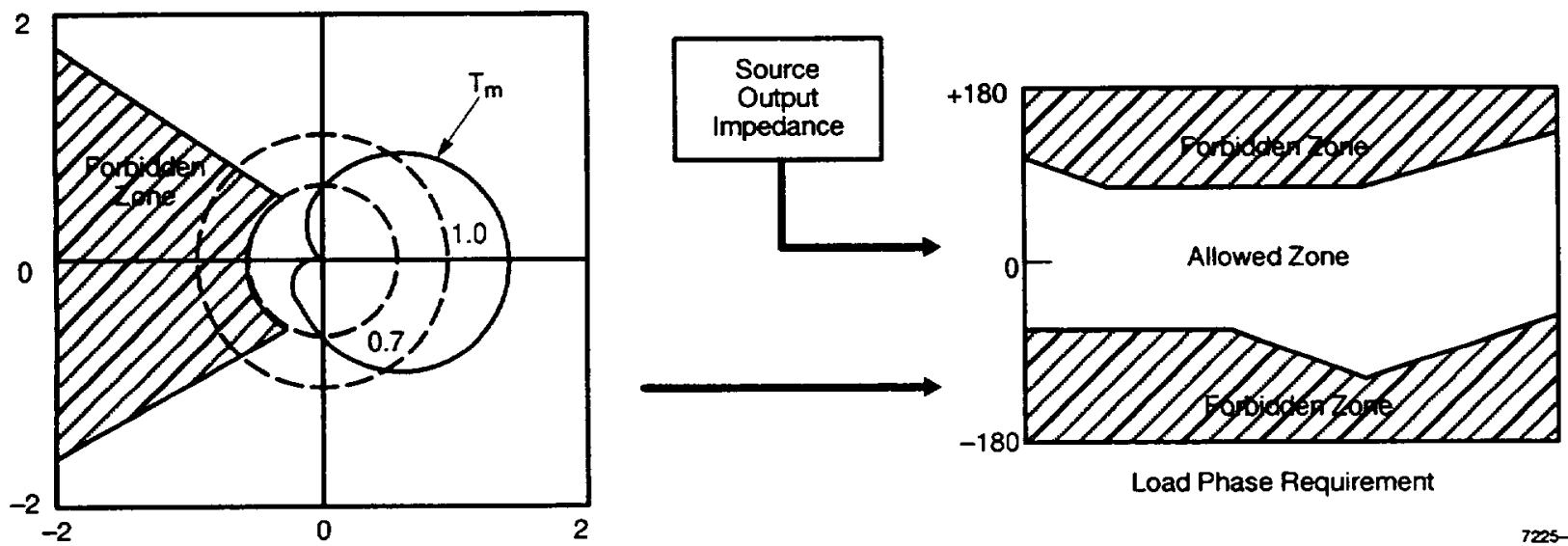

$7225-3$

FIGURE 6. A NYQUIST DIAGRAM SHOWING THE FORBIDDEN ZONE DEFINED BY PHASE AND GAIN MARGINS OF $30 \mathrm{deg}$ AND $3 \mathrm{~dB}$, AND A SAMPLE CORRESPONDING BODE PLOT LOAD PHASE REQUIREMENT

design constraints. This includes factors such as EMI requirements (which drive filter designs), orbital replacement unit (ORU) efficiency, cable characteristics, inrush, and ripple requirements. On Space Station, these factors were taken into account to establish explicit input and output impedance requirements on all primary system ORUs. In the secondary system, the output impedance of the DDCUs have been specified such that the desired bus impedance margins ( $3 \mathrm{~dB}$ and $30 \mathrm{deg}$ ) would be met at the DDCU output ports with any combination of reasonable, expected loads. Therefore, to avoid unnecessary cost impacts, no explicit load impedance requirements were placed on the load converters in the secondary system; the output impedance requirements placed on the DDCU were intended to accommodate a very wide range of possible designs. (Also, additional specific guidelines for the design of load converters are contained in an appendix to the program-wide Power Quality Specification.)

\section{LOAD IMPEDANCE SPECIFICATION}

Phase and gain margins are each defined at only a single frequency (determined on the Nyquist diagram by the bus impedance intercept points on the unit circle and negative $x$-axis, respectively) and does not specifically guarantee good margin between the crossover points. But as shown in Figure 6, the combination of specified phase and gain margins allows a forbidden zone to be defined in the complex plane that applies to all frequencies where impedance overlap occurs. This provides a complete small signal stability criterion since it absolutely ensures that the -1 point will not be encircled.

This forbidden zone approach works because it allows the placement of absolute phase requirements on loads. The resulting combination of source and load requirements more rigorously ensures proper margins in the system, contributes to good bus performance, and prevents the system from being conditionally stable. An updated edition of the ISS Power Quality Specification is in work which is intended to impose impedance requirements on future loads, based on this more-explicit forbidden zone approach. The approach is applied as follows: given the designed source impedance of the source converter (the DDCU for the Space Station), the forbidden region on the Nyquist plot can be transformed into load impedance magnitude and phase specifications on a Bode plot. The magnitude of the source impedance is first plotted. This defines the lower boundary for which there will be no interaction with the load impedance magnitude; this is an intrinsically stable case. However, if there is cross-over (as illustrated in Fig. 4b), then a phase requirement can be applied over the entire overlap region. To obtain it, the source phase requirement is graphed on a Bode plot, and then the desired phase margin is applied. Only those regions of this phase plot that preserve the desired margin are allowed, and become the phase specification for the load converter (or aggregate load subsystem).

\section{ANALYSIS AND TEST APPROACH FOR LARGE SIGNAL STABILITY}

These impedance requirements govem small signal (steadystate) stability of the integrated system, but do not guarantee large signal (transient) stability for the entire EPS. So, for large signal stability, it is important to explicitly include two other techniques in designing and building a dc power system. Computer analysis and hardware testing form the other legs of a stability triad which should always be applied to the development of a complex system. As mentioned previously, this is being employed on the ISS program. Computer models are being developed along with the hardware designs for both source and load converters as well as for the cables and switchgear. These computer models are being exercised extensively to predict transient and nonlinear characteristics of the system, as well as potential interactions between loads. Figure 7 shows an example of a model of a secondary network on the space station showing the aggregate load impedance of multiple loads being fed from a single DDCU. Light and heavy loading cases are shown, both as a Bode plot with crossover points, and as a Nyquist 


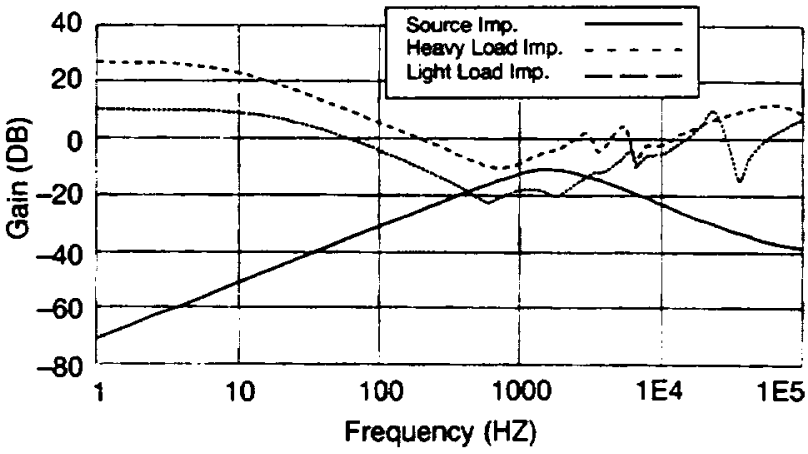

(a) ZS/ZI at DDCU Output/Light and Heavy Loading Conditions

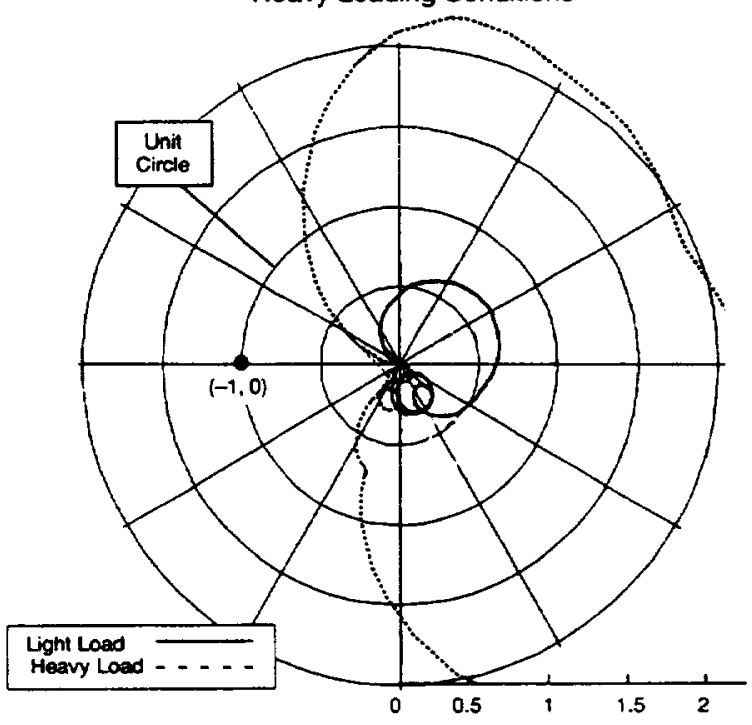

(b) ZSRI at DDCU Output/light and Heavy Loading Conditions

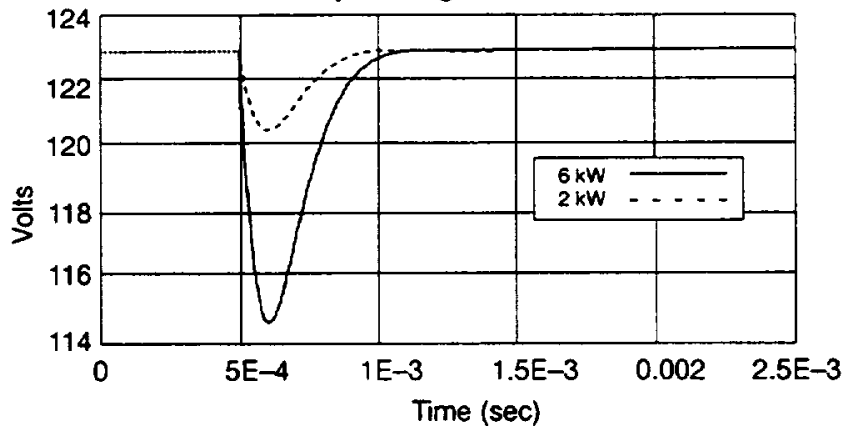

(c) Bus response at DDCU output: Step Load Changes from $480 \mathrm{~W}$ to $2 \mathrm{~kW}$ and $6 \mathrm{~kW}$

FIGURE 7. SECONDARY NETWORK MODEL SHOWING AGGREGATE LOAD IMPEDANCE

plot of $Z_{S} / Z_{L}$. Additionally, the transient bus response to step loads is also shown indicating rapid system recovery and good damping characteristics.
It is expected that the extensive hardware testing and analysis activities planned by the program will identify any EPS scenarios which degrade power quality or pose problems to system stability. Then the loads, or combination of loads, which are involved can be specifically addressed. To address large signal stability of the ISS power system, transient stability test requirements for loads and sources have been developed. These requirements include various large signal tests for sources that included line and load changes under various bus voltages and loading scenarios. The loads are also required to maintain stability under line and load step changes. Actual laboratory testing of prototype and engineering model hardware has been an increasingly active part of the program as more and more hardware becomes available. Already, versions of all the primary system hardware have been tested together, and representative system testing for the secondaries has started. Because the ISS will always be changing over the lifetime of the station, all three phases of the stability triad will be continuously applied as new payloads are flown, and as core system hardware is upgraded.

\section{SUMMARY}

A stability approach has been developed for the International Space Station, which is applicable to any large dc power system. It is based on establishing a set of phase and gain requirements at key subsystem interface points throughout the system, which provide good confidence that the system will be stable under small signal conditions, with reasonable performance margin. To address transient behavior, and interactions between loads, two additional stages are key in providing a stable system in flight: computer modeling and hardware verification testing. This three-pronged approach will catch any problems as early as possible and yet provides a practical and viable technique to ensure a robust and stable power system.

\section{REFERENCES}

Lee, J. R., Cho, B. H., Kim, S. I., Lee, F. C., 1988, "Modeling and Simulation of Spacecraft Power Systems," IEEE Transactions on Aerospace and Electronic Systems, Vol. 24, No. 3, May 1988 pp. 295-303

Gholdston, E. W., Hartung, J., and Friefeld, J., 1995, "Current Status, Architecture, and Future Technologies for the International Space Station," IEEE Aerospace and Electronic Systems Magazine, Feb 1996, Vol. 11, No.2, pp. 25-30.

Karimi, K., and Fu, J., 1994,"Modeling and Simulation of the Space Station LAB Module Electric Power System," IECEC 1994, pp. 345-350.

Wildrick, C. M., Lee, F. C., Cho, B. H., and Choi, B., 1993, "A Method of Defining the Load Impedance Specification for A Stable Distributed Power System," PESC 1993, pp.826-832.

Middlebrook, R. D., 1976, "Input Filter Considerations in Design and Applications of Switching Regulators," IEEE Industry Applications Society Annual Meeting Record, pp. 366-382.

Yotsumoto, K., Muroyama, S., Matsurziuru, S., Watanabe, H., 1988, "Design for a Highly Efficient Distributed Power Supply System Based on Reliability Analysis," Tenth International Telecommunication Energy Conference, pp. 545-550. 



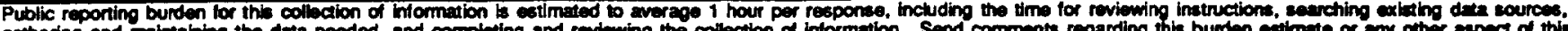

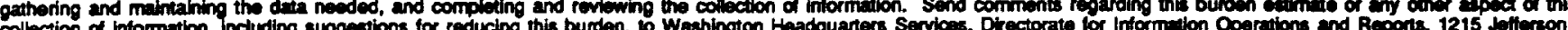
Davis Highwey, Suhe 1204, Aitington, VA $22202-400$, and to the Office of Management and Budget, Paperwork Reduction Project (0704-0188), Washington, DC 20503.

\begin{tabular}{|c|c|c|}
\hline 1. AGENCY USE ONLY (Leave blank $)$ & $\begin{array}{c}\text { 2. REPORT DATE } \\
\text { July } 1996\end{array}$ & $\begin{array}{r}\text { 3. REPOFT TYPE AND DATES COVERED } \\
\text { Technical Memorandum }\end{array}$
\end{tabular}

\section{TITLE AND SUBTITLE}

5. FUNDING NUMBERS

Stability of Large DC Power Systems Using Switching Converters, With Application to the International Space Station

6. AUTHOA(S)

E.W. Gholdston, K. Karimi, F.C. Lee, J. Rajagopalan, Y. Panov, and B. Manners

7. PERFOAMMG ORGANZATION NAME(S) AND ADDRESS(ES)

National Aeronautics and Space Administration

Lewis Research Center

Cleveland, Ohio 44135-3191
WU-323-99-01

8. PERFOAMNG ORGANIZATION REPORT NUMBER

E-10356
9. SPONSORINGMONTORING AGENCY NAME(S) AND ADDRESS(ES)

National Aeronautics and Space Administration

Washington, D.C. 20546-0001
10. SPONSOPINGMONITOPING AGENCY REPORT NUMBER

NASA TM-107281

IECEC 96-96079

11. SUPPLEMENTARY NOTES

Prepared for the 31st Intersociety Energy Conversion Engineering Conference cosponsored by IEEE, AIChE, ANS, SAE, AIAA, and ASME, Washington, D.C., August 11-16, 1996. E.W. Gholdston, Rocketdyne Division, Rockwell International, 6633 Canoga Park, Califomia 91309; K. Karimi, The Boeing Company, P.O. Box 3707, Seattle, Washington 98124; F.C. Lee, J. Rajagopalan, and Y. Panov, Virginia Polytechnic Institute and State University, 667 Whittenmore Hall, Blacksburg, Virginia 24061-0111 (work performed under NASA Grant NAG3-1349); B. Manners, NASA Lewis Research Center. Responsible person, B. Manners, organization code 6910, (216) 433-8341.

12a. DISTRIBUTRONAVAILABILTY STATEMENT

12b. DISTRIBUTKON CODE

Unclassified - Unlimited

Subject Categories 18,20 , and 33

This publication is available from the NASA Center for AeroSpace Information, (301) 621-0390.

13. ABSTRACT (Maximum 200 words)

As space direct current (dc) power systems continue to grow in size, switching power converters are playing an ever larger role in power conditioning and control. When designing a lange de system using power converters of this type, special attention must be placed on the electrical stability of the system and of the individual loads on the system. In the design of the electric power system (EPS) of the Intemational Space Station (ISS), the National Aeronautics and Space Administration (NASA) and its contractor team led by Boeing Defense \& Space Group has placed a great deal of emphasis on designing for system and load stability. To achieve this goal, the team has expended considerable effort deriving a ciear concept on defining system stability in both a general sense and specifically with respect to the space station. The ISS power system presents numenous challenges with respect to system stability, such as high power, complex sources and undefined loads. To complicate these issues, source and load components have been designed in parallel by three major subcontractors (Boeing, Rocketdyne, and McDonnell Douglas) with interfaces to both sources and loads being designed in different countries (Russia, Japan, Canada, Europe, etc.). These issues, coupled with the program goal of limiting costs, have proven a significant challenge to the program. As a result, the program has derived an impedance specification approach for system stability. This approach is based on the significant relationship between source and load impedances and the effect of this relationship on system stability. This approach is limited in its applicability by the theoretical and practical limits on component designs as presented by each system segment. As a result, the overall approech to system stability implemented by the ISS program consists of specific hardware requirements coupled with extensive system analysis and hardware testing. Following this approach, the ISS program plans to begin construction of the world's largest orbiting power system in 1997.

14. SUBJECT TEAMS

Power electronics; Stability; DC/DC converters; Space station

17. SECURITY CLASSIFICATION
OF REPORT
Unclassified

NSN 7540-01-280-5500
18. SECURTY CLASSIFICATION OF THIS PAGE Unclassified
19. SECURTY CLASSIFICATYN OF ABSTRACT Unclassified

\begin{tabular}{|} 
15. NUMBER OF PAGES \\
8 \\
\hline 16. PAICE CODE \\
$\mathrm{AO} 2$ \\
\hline
\end{tabular}

20. LMITATION OF ABSTRACT 


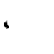




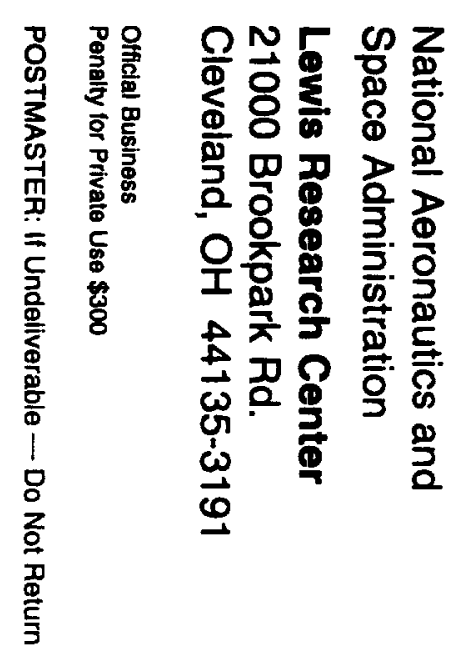

